OPEN ACCESS

Edited by: Hermann Einsele,

Julius Maximilian University of Würzburg, Germany

Reviewed by:

Ignacio Anegon,

Institut National de la Santé et de la

Recherche Médicale (INSERM), France Luiza Guilherme,

University of São Paulo, Brazi

${ }^{*}$ Correspondence: Xiao-Kang L ri-k@ncchd.go.jp

Specialty section: This article was submitted to Alloimmunity and Transplantation,

a section of the journal

Frontiers in Immunology

Received: 13 July 2020 Accepted: 31 August 2020 Published: 14 October 2020

Citation:

Que W, Guo W-Z and Li X-K (2020) Manipulation of Regulatory Dendritic

Cells for Induction Transplantation

Tolerance.

Front. Immunol. 11:582658 doi: 10.3389/fimmu.2020.582658

\section{Manipulation of Regulatory Dendritic Cells for Induction Transplantation Tolerance}

\author{
Weitao Que ${ }^{1,2}$, Wen-Zhi Guo ${ }^{1}$ and Xiao-Kang Li ${ }^{1,2 *}$ \\ ${ }^{1}$ Department of Hepatobiliary and Pancreatic Surgery, The First Affiliated Hospital of Zhengzhou University, Zhengzhou, \\ China, ${ }^{2}$ Division of Transplantation Immunology, National Research Institute for Child Health and Development, Tokyo, Japan
}

Current organ transplantation therapy is life-saving but accompanied by well-recognized side effects due to post-transplantation systematic immunosuppressive treatment. Dendritic cells (DCs) are central instigators and regulators of transplantation immunity and are responsible for balancing allograft rejection and tolerance. They are derived from monocyte-macrophage DC progenitors originating in the bone marrow and are classified into different subsets based on their developmental, phenotypical, and functional criteria. Functionally, DCs instigate allograft immunity by presenting donor antigens to alloreactive $T$ cells via direct, indirect, and semidirect recognition pathways and provide essential signaling for alloreactive $T$ cell activation via costimulatory molecules and pro-inflammatory cytokines. Regulatory DCs (DCregs) are characterized by a relatively low expression of major histocompatibility complex, costimulatory molecules, and altered cytokine production and exert their regulatory function through $\mathrm{T}$ cell anergy, $\mathrm{T}$ cell deletion, and regulatory $T$ cell induction. In rodent transplantation studies, DCreg-based therapy, by in situ targeting or infusion of ex vivo generated DCregs, exhibits promising potential as a natural, well-tolerated, organ-specific therapeutic strategy for promoting lasting organ-specific transplantation tolerance. Recent early-phase studies of DCregs have begun to examine the safety and efficacy of DCreg-induced allograft tolerance in living-donor renal or liver transplantations. The present review summarizes the basic characteristics, function, and translation of DCregs in transplantation tolerance induction.

Keywords: allograft, dendritic cell, $\mathrm{T}$ cell, tolerance, transplantation

\section{INTRODUCTION}

Organ transplantation has progressed greatly over the past half-century to become the optimal treatment for a variety of end-stage organ diseases. However, the life-long, systemic immune suppression after a transplantation has major associated adverse effects, including severe infections, malignancies, psychosocial issues affecting patients, and a high cost to the health care system $(1,2)$. Immunosuppressive drugs can prevent acute cellular rejection but fail to control donor-specific antibody production and later-phase chronic organ rejection that may eventually lead to graft failure (3-5). Donor-specific tolerance is recognized as superior to systemic immunosuppression in being more conducive to donor organ acceptance without compromising host protective immunity. In this context, regulatory immune cell-based therapies are emerging as novel, promising strategies for establishing permanent donor-specific immune tolerance and minimizing or even obviating 
the need for immunosuppressive drugs after organ transplantation. Many types of regulatory immune cells, such as regulatory $\mathrm{T}$ cells (Tregs) (6), type 1 regulatory $\mathrm{T}$ cells ( $\operatorname{Tr} 1)(7)$, regulatory macrophages, regulatory $\mathrm{B}$ cells (Bregs) $(5,8)$, myeloid-derived suppressor cells (9), and regulatory dendritic cells (DCregs) (10), have already been investigated in animal transplantation models, and entered the clinical trials in organ transplantation and shown clear benefits in terms of safety and graft survival $(11,12)$. Among these cells, DCregs are particularly attractive due to their role as central regulators of the immune response.

\section{BASIC PROFILE OF DCs}

DCs are a rare, heterogeneous population of the most efficient antigen-presenting cells (APCs) derived from bone marrow. They play a critical role in the instigation and regulation of the immune response $(13,14)$. DCs are distributed ubiquitously throughout the body and serve as immunologic sentinels specialized in sensing danger signals and capturing, processing, and presenting antigenic materials $(13,15-17)$. DCs can initiate both the innate and adaptive immune responses, for example, via natural killer (NK) cells and cytotoxic T cells. In these processes, DCs undergo complicated phenotypical and functional changes in response to the environment, signals, and antigens (18).

Based on their developmental, phenotypical, and functional features, DCs can be categorized into several different subsets. Traditionally, DCs were subdivided into classical or conventional DCs (cDCs), plasmacytoid DCs (pDCs), monocyte-derived DCs (MoDCs), and langerhans cells (LCs) (19). All subsets of DCs express major histocompatibility complex (MHC) class II and CD11c surface molecular markers. The cDC subtype regularly located in lymphoid organs and most non-lymphoid organs has a superior ability to capture, process, and present antigens to naïve $\mathrm{T}$ cells. Indeed, studies of transgenic mice, constitutive or conditionally deficient in cDCs, have confirmed the central role of $\mathrm{cDCs}$ in priming the naïve $\mathrm{T}$ cell response $(20,21)$. The $\mathrm{cDC}$ subtypes can be further subdivided into $\mathrm{CDC} 1$ $(\mathrm{CD} 8 \alpha+/ \mathrm{CD} 103+$ in mice; $\mathrm{CD} 141+$ in humans) and $\mathrm{cDC} 2$ $(\mathrm{CD} 11 \mathrm{~b}+$ in mice; $\mathrm{CD} 1 \mathrm{c}+$ in human) subsets. Moreover, the cDC1 subset is adept in cross-presentation and priming CD8+ cytotoxic $\mathrm{T}$ cells while the cDC2 subset is most proficient at driving the CD4+ $\mathrm{T}$ cell response (22-24). The pDCs patrolling the blood and peripheral organs excel in producing high levels of type I IFN in response to viruses and RNA/DNA or immune complexes, a direct consequence of their constitutively expressing IRF7 $(25,26)$. They also participate in antigen presentation, control the $\mathrm{T}$ cell response, and usually exhibit tolerogenic properties by favoring the generation of Tregs $(27,28)$. MoDCs, also known as inflammatory DCs, derive from monocytes infiltrating under inflammatory conditions and are capable of releasing large amounts of tumor necrosis factor alpha (TNF$\alpha$ ) and inducible nitric oxide synthase (iNOS) upon pathogen recognition (29). Although identified as a subset of DCs, MoDCs share many features with both cDCs and macrophages, and their classification is still debated $(30,31)$. LCs are a distinct subset of DCs resident in the epidermal layer of the skin. Although LCs are similar to cDCs in terms of phenotype and function, they also have unique differentiation and homeostatic features $(19,32)$. LCs are generated from embryonic hematopoietic precursors which are seeded in the skin in the prenatal period and self-renew in situ at a very low rate under physiological steady-state conditions without replenishment by blood-borne precursors $(33,34)$. In contrast to cDCs, LC development is independent of FMS-like tyrosine kinase 3(Flt3) and Flt3 ligand (Flt3L) but requires colony-stimulating factor 1 receptor (Csf1R) like many tissue-resident macrophages, such as microglial cells and Kupffer cells $(35,36)$. Recently, IL-34 has been identified as the second functional ligand for Csf-1R and was required for the development of LCs and microglial cells (37). In the current classification of DCs, it is unclear whether DCregs constitute an independent DC subset or represent a specific functional state of DCs. In fact, most DC subsets can exert regulatory function through T cell anergy, T cell deletion, and Treg induction $(38,39)$.

The lifespan of DCs is generally short, and continuous replenishment from bone marrow progenitors is essential to maintaining DC homeostasis (40). Except for LCs, the majority of DC subsets originate from the same progenitors, namely monocyte-macrophage DC progenitors (MDPs), which reside in the bone marrow $(19,41)$ (Figure 1). MDPs further give rise to common monocyte progenitors (cMoPs) and common DC progenitors (CDPs) $(42,43)$. cMoPs develop into blood monocytes in the bone marrow but further differentiate into MoDCs in tissue as a consequence of inflammation or infection $(29,43-46)$. CDPs further give rise to pDCs and pre-DCs (47, 48). pDCs terminally differentiate into fully developed cells in the bone marrow, then migrate out to patrol the blood and peripheral organs $(49,50)$. Pre-DCs migrate out of the bone marrow through the blood to seed non-lymphoid and lymphoid organs, where they terminally differentiate into cDCs $(36,51,52)$. LCs derive predominantly from embryonic fetal liver monocytes with a minor contribution from yolk sac-derived macrophages and are maintained locally by self-renewal under steady-state conditions $(33,53)$. In severe inflammatory conditions, LCs are replaced by blood-borne monocytes and acquire the capacity for self-renewal $(35,54)$.

\section{FUNCTION OF DCs IN TRANSPLANTATION}

DCs are critical to linking the innate and adaptive response in transplantation, in other words, to initiating robust, donorspecific, alloreactive $\mathrm{T}$ cell activation. During a classical immune response, immature DCs sense the presence of damage- and pathogen-associated molecular patterns (DAMPs and PAMPs), the so-called "Signal 0s," from damaged cells and microbial molecules, respectively, via pattern recognition receptors (PRRs) $(55,56)$. These PRRs mediate internalized antigens and their routing to antigen-processing pathways (57). Subsequently, PRRs activate a series of intracellular pro-inflammatory molecular signaling cascades, such as interferon-responsive factor and nuclear factor kappa B pathways $(58,59)$. Activation of these signaling pathways leads to maturation of DCs, characterized 


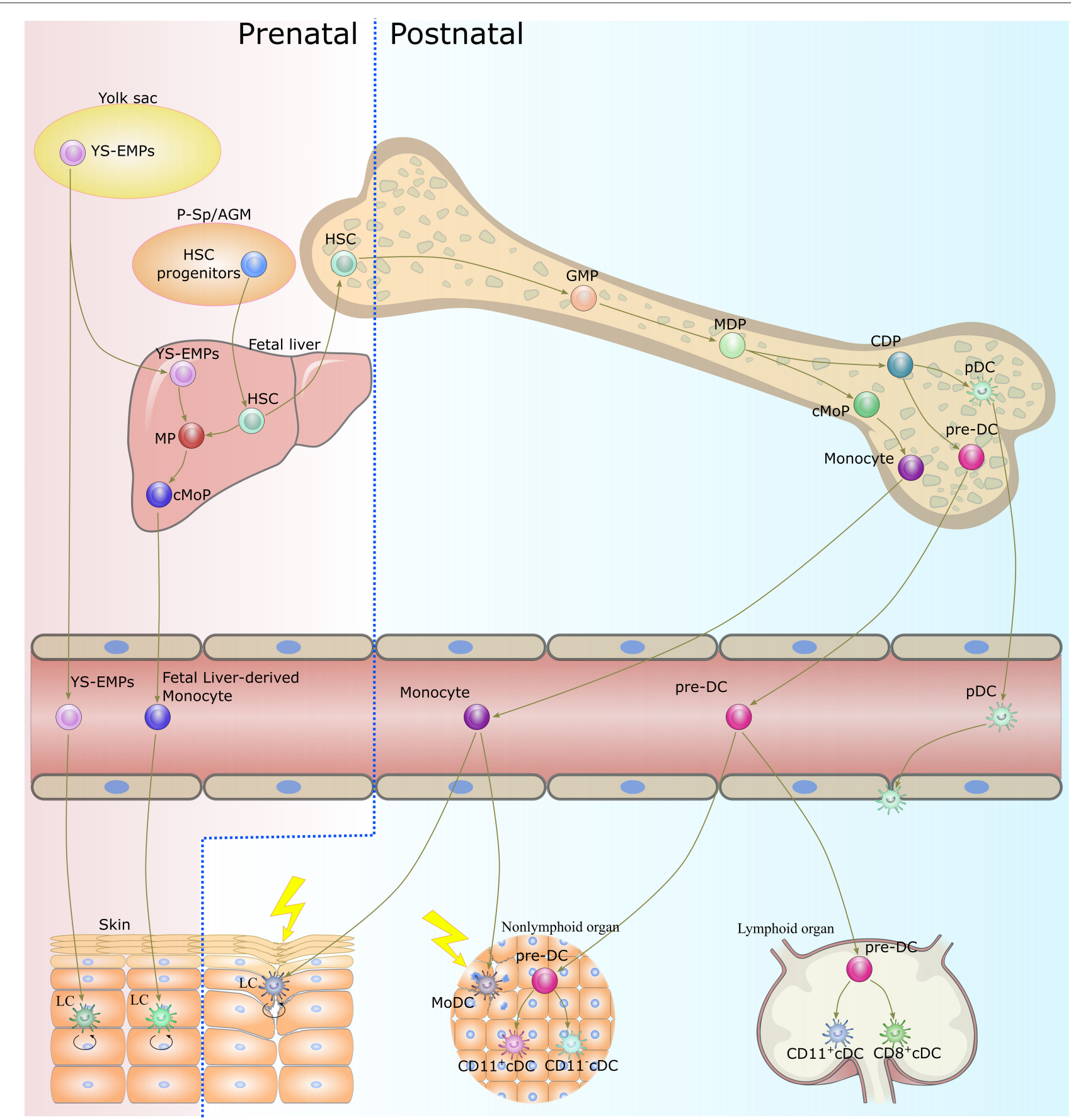

FIGURE 1 | Origin and development of dendritic cells. With the exception of LCs, DCs develop from bone marrow-derived precursors. CDPs give rise to cDCs and pDCs. Monocytes differentiate into MoDCs in tissue as a consequence of inflammation or infection. LCs originate in prenatal precursor cells and are maintained locally by self-renewal under steady-state conditions. While under a severe inflammatory condition, LCs are replaced by blood-borne monocytes and acquire the capacity of self-renewal. DC, dendritic cell; LC, langerhans cells; CDP, common dendritic cell progenitor; CDC, classical dendritic cell; pDC, plasmacytoid dendritic cell; MoDC, monocyte-derived dendritic cell; YS-EMPs, Yolk sac-derived erythromyeloid progenitor cells; P-Sp/AGM para-aortic splanchnopleure/aorta, gonads, and mesonephros; HSC, hematopoietic stem cells; CMP, common myeloid progenitor cell; MP, myeloid progenitor cell; cMoP, common monocyte progenitor; GMP, granulocyte-macrophage progenitor; MDP, monocyte-macrophage DC progenitor.

by upregulation of MHC molecules, costimulatory molecules (e.g., CD80, CD86), chemokine receptors (e.g., C-C chemokine receptor type 7, CCR7), adhesion molecules (e.g., CD62L), and pro-inflammatory cytokines (e.g., TNF- $\alpha$, IL-12) (60-62). Chemokine receptors and adhesion molecules permit DCs to migrate to lymphoid organs, where they contact and prime $\mathrm{T}$ 
cells (63-65). Antigens loaded on MHC class I molecules are presented to $\mathrm{CD} 8+\mathrm{T}$ cells, whereas antigens loaded on MHC class II molecules are presented to CD4+ T cells. Costimulatory molecules and pro-inflammatory cytokines provide the essential signals for $\mathrm{T}$ cell activation $(66,67)$.

Unlike immune responses to conventional antigens, the trigger of allograft immunity relies on both donor- and hostderived DC-mediated antigen recognition (Figure 2). Following transplantation, donor-derived DCs migrate out of the graft to the graft-draining lymphoid tissues, where they directly present intact, donor (allogeneic) MHC molecules to alloreactive $\mathrm{T}$ cells. The direct allorecognition pathway is considered to dominate primary immune responses following allografting, which leads to acute graft rejection. The donor-derived DCs are rapidly eliminated by the early response of NK cells. Thus, direct allorecognition decreases along with a drop in the number of donor-derived DCs after transplantation. Meanwhile, host-derived DCs capture, process, and present donor-derived antigens to alloreactive $\mathrm{T}$ cells via the indirect pathway. These donor-derived antigens originate in damaged donor cells within a graft or in dying donor-derived DCs within draining secondary lymphoid organs. The indirect allorecognition pathway partially contributes to the early alloresponses and gradually dominates, leading to alloantibody production and chronic rejection. In addition, alloreactive $\mathrm{T}$ cells can also be stimulated via the semidirect allorecognition pathway, i.e., the recognition of intact donor MHC molecules transferred to host DCs by cell-cell contact or extracellular vesicles. The semidirect allorecognition pathway generates effector T cells that are donor MHC-restricted, as with the direct allorecognition pathway. Although each of these allorecognition pathways can solely or synergistically lead to allograft rejection, the maturity of DCs greatly influences the magnitude and quality of the T cell response (68-70).

$\mathrm{T}$ cells are critical players in transplantation immunity, which directly mediates allograft rejection. The activation of alloreactive T cells depends on three distinct DC-derived signals, including T-cell receptor engagement (signal 1), costimulation (signal 2), and cytokine stimulation (signal 3) (66). These DC-derived signals determine the fate of alloreactive $\mathrm{T}$ cells and tilt the balance toward graft survival or rejection (71). DCregs comprise a heterogeneous population of immature or semi-mature DCs characterized by a relatively low expression of MHC class II molecules, costimulatory molecules, and altered cytokine production. DCregs are thought to exert their regulatory function through various mechanisms (Figure 3). With the presentation of low levels of antigens in the absence of costimulatory molecules, such as CD80 and CD86, T cells will become anergic and lose their ability to proliferate $(72,73)$. The presence of coinhibitory signals during $\mathrm{T}$ cell activation, such as programmed cell death $1(\mathrm{PD}-1)$ and $\mathrm{PD}$ ligand $1(\mathrm{PD}-\mathrm{L} 1)$ interaction, CD80/CD86 and cytotoxic T lymphocyte antigen 4 (CTLA-4) interaction, inducible T-cell costimulator (ICOS) and ICOS ligand (ICOS-L) interaction, and heme oxygenase-1 (HO1), can also lead to T cell anergy (74-78). HO-1 expression was also shown to be beneficial to DC survival and immunoregulatory properties $(79,80)$. Altered cytokine production; low levels of pro-inflammatory cytokines, such as IL-12; and high levels of anti-inflammatory cytokines, such as transforming growth factor $\beta$ (TGF- $\beta$ ) and IL-10 mediate T cell anergy and Treg induction (81). DCregs can also induce clonal deletion of alloreactive $\mathrm{T}$ cells via the Fas/FasL pathway or indoleamine 2,3-dioxygenase (IDO)-induced apoptosis $(82,83)$. Furthermore, DCregs can induce several subtypes of regulatory lymphocytes, including classical Foxp3+ Tregs, Tr1, CD8+ Tregs, and Bregs via mechanisms involving direct cell-cell interaction signaling through surface molecules (e.g., immunoglobulin-like transcript (ILT)-3/4, CTLA-4, PD-L1, FasL, ICOS-L, and others), as well as the immunosuppressive milieu through secretory factors (e.g., IL-10, TGF- $\beta$, IL-27, IL-35, IDO, retinoic acid, adenosine, HO1 , and nitric oxide). DCregs and Tregs interact with each other through a self-maintaining regulatory loop required for maintaining immune tolerance (84).

\section{EX VIVO GENERATED DCregs}

DCreg induction has been intensively studied for its potential therapeutic value in transplantation (Figure 4). The current literature has described various protocols for generating DCregs ex vivo. Generally, DCregs are generated from bone marrow precursors in rodents and from CD34+ hematopoietic precursors or blood monocytes (CD14+) in humans (85). The most widely used strategy is the deployment of culture progenitors using granulocyte-macrophage colony-stimulating factor (GM-CSF) \pm IL-4 with the addition of one or more pharmacological agents that stably inhibit their maturation and promote their tolerogenicity $(86,87)$. GM-CSF is a critical cytokine required for ex vivo DC generation, but some researchers have used Flt3L instead of GM-CSF for DCreg differentiation $(88,89)$. The pharmacological agents include IL-10, dexamethasone, vitamin D3, rapamycin, and others $(87,90,91)$. DCregs conditioned by IL-10 are resistant to maturation and are capable of inducing antigen-specific $\mathrm{T}$ cell anergy and Treg activity (92-94). IL-10-modulated DCs are the most suitable candidate for DC-based transplantation tolerance induction therapy (95). IL-10-induced monocytederived DCregs, characterized by a high IL-10/IL-12 ratio and high expression levels of tolerogenic molecules, HLA-G and ILT4 , are potent inducers of adaptive $\operatorname{Tr} 1$ cells (96). Dexamethasoneinduced DCregs express low levels of costimulatory molecules but high levels of inhibitory receptors, ILT-2 and ILT-3, and produce high amounts of IL-10 and IDO $(95,97,98)$. Vitamin D3 and its analogs promote the tolerogenic phenotype of DCreg via the induction of effector $\mathrm{T}$ apoptosis and generation of antigen-specific Tregs $(90,99,100)$. The combined use of dexamethasone and vitamin D3 leads to "alternatively activated" DCs with an enhanced migration ability inducing memory $\mathrm{T}$ cell hyporesponsiveness while skewing naive $\mathrm{T}$ cells toward a low IFN- $\gamma /$ high IL-10 cytokine profile $(101,102)$. Rapamycinconditioned DCs have attracted much attention for their role in alloantigen Foxp3+ Treg expansion and migratory activity via enhancing CCR7 expression $(91,103)$.

Although pharmacological conditioning offers effective strategies for ex vivo generation of DCregs, there are some 


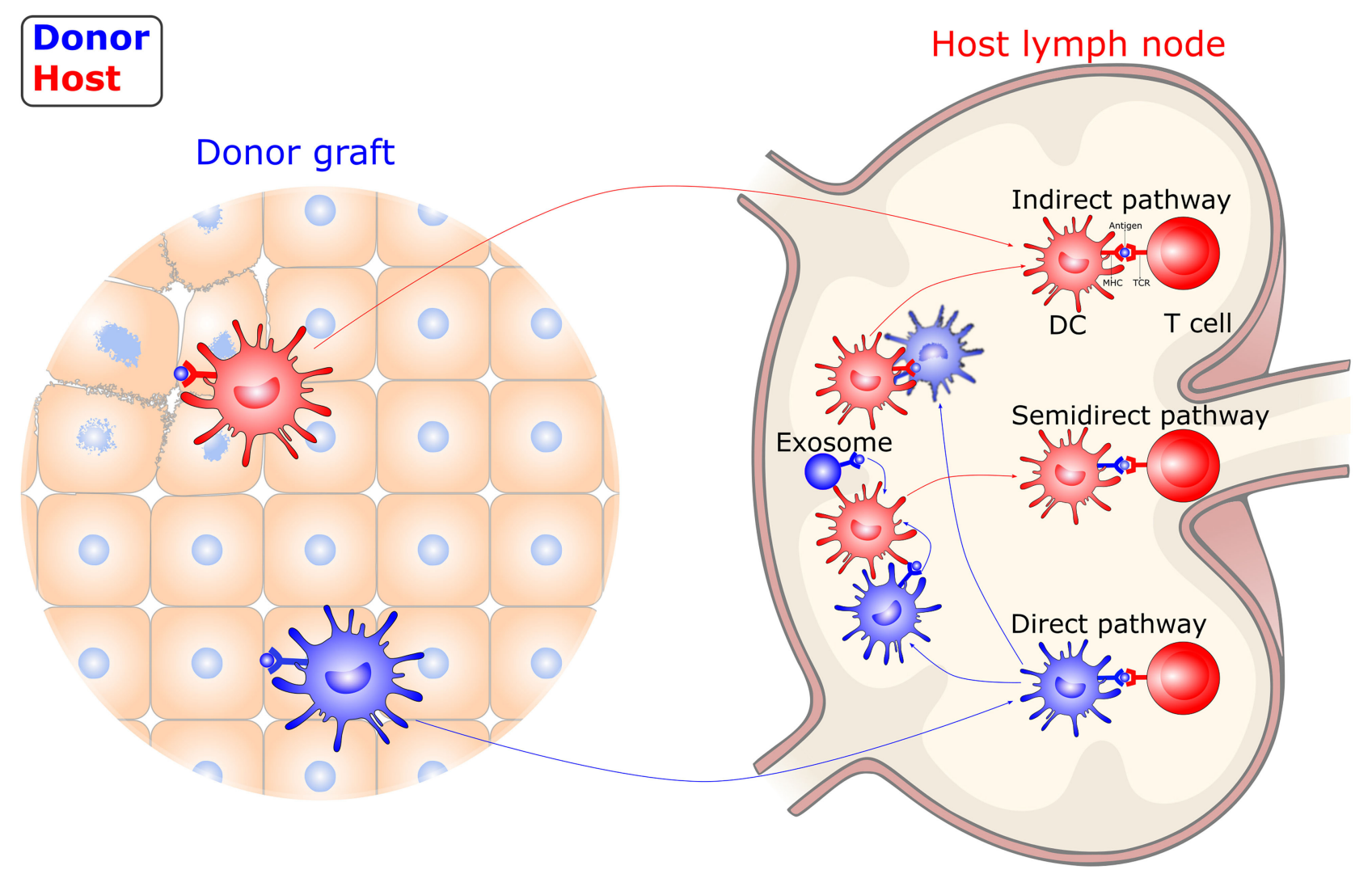

FIGURE 2 | Allorecognition pathways in transplantation. DCs instigate allograft immunity by presenting donor antigens to alloreactive T cells via direct, indirect, and semidirect recognition pathways. In the direct pathway, donor-derived DCs directly present intact donor (allogeneic) MHC molecules to alloreactive T cells. In the indirect pathway, host-derived DCs present donor-derived antigens, captured from damaged graft tissue or dying, donor-derived DCs, to alloreactive T cells. In the semidirect pathway, intact donor $\mathrm{MHC}$ molecules transferred to host DCs by cell-cell contact or extracellular vesicles are recognized. DC, dendritic cell; MHC, major histocompatibility complex; TCR, T-cell receptor.

limitations in ex vivo-generated DCregs, such as undesirable pro-inflammatory factors, rematuration in vivo, and low migratory activity. Genetic manipulation by adenovirus vectors and small interfering RNAs (siRNAs) provides a powerful tool for modifying specific features of ex vivo-generated DCregs (104). Previous studies have reported that gene silencing of CD80/CD86 and IL-12 promoted the regulatory activity of DCregs $(105,106)$. Genetic interference with NF- $\kappa B$ induced a stable immature state by preventing the rematuration of DCregs (107). Dong et al. reported that concurrent CCR7 overexpression and RelB knockdown in DCregs displayed enhanced migratory and regulatory activity (108).

In addition to DCregs generated naturally from progenitor cells, we generated DCregs from murine induced pluripotent stem cells (iPSCs), which were able to remain in a stable immature state even under strong stimulation (109). iPSCderived DCregs worked as a therapeutic cellular vaccine to generate Tregs and induced donor-specific allograft acceptance. Other researchers have explored using human PSCs, including iPSCs and embryonic stem cells, as a source of DCs for immune therapy (110-112). These studies have highlighted the potential of PSC-derived DCregs in clinical transplantation.

As discussed above, transplantation immunity involves both donor- and host-derived DCs via three allorecognition pathways. Therefore, there is a question of whether DCregs should be derived from the donor or the host. It is also worth noting that the risk of host-sensitization to donor antigens due to the presence of transferred allogeneic molecules should be taken into consideration in DCreg-based therapy. The therapeutic efficacy of DCregs in organ transplantation was first examined by Rastellini et al. and Fu et al. $(113,114)$. Donor-derived DCregs, infused 1 week before transplantation, significantly prolonged the survival of murine non-vascularized (pancreatic islet) and vascularized (heart) allografts. Alloantigen-specific T-cell anergy was observed in vitro. Subsequently, the role of DCreg-based therapy was explored extensively in multiple transplantation models and clinical studies (10). The sources of the DCregs included donor-derived DCregs and host-derived DCregs, either pulsed or unpulsed with donor antigens. Additional host treatment, including costimulation blockade, conventional immunosuppressive drugs, and lymphocyte depletion, was used 


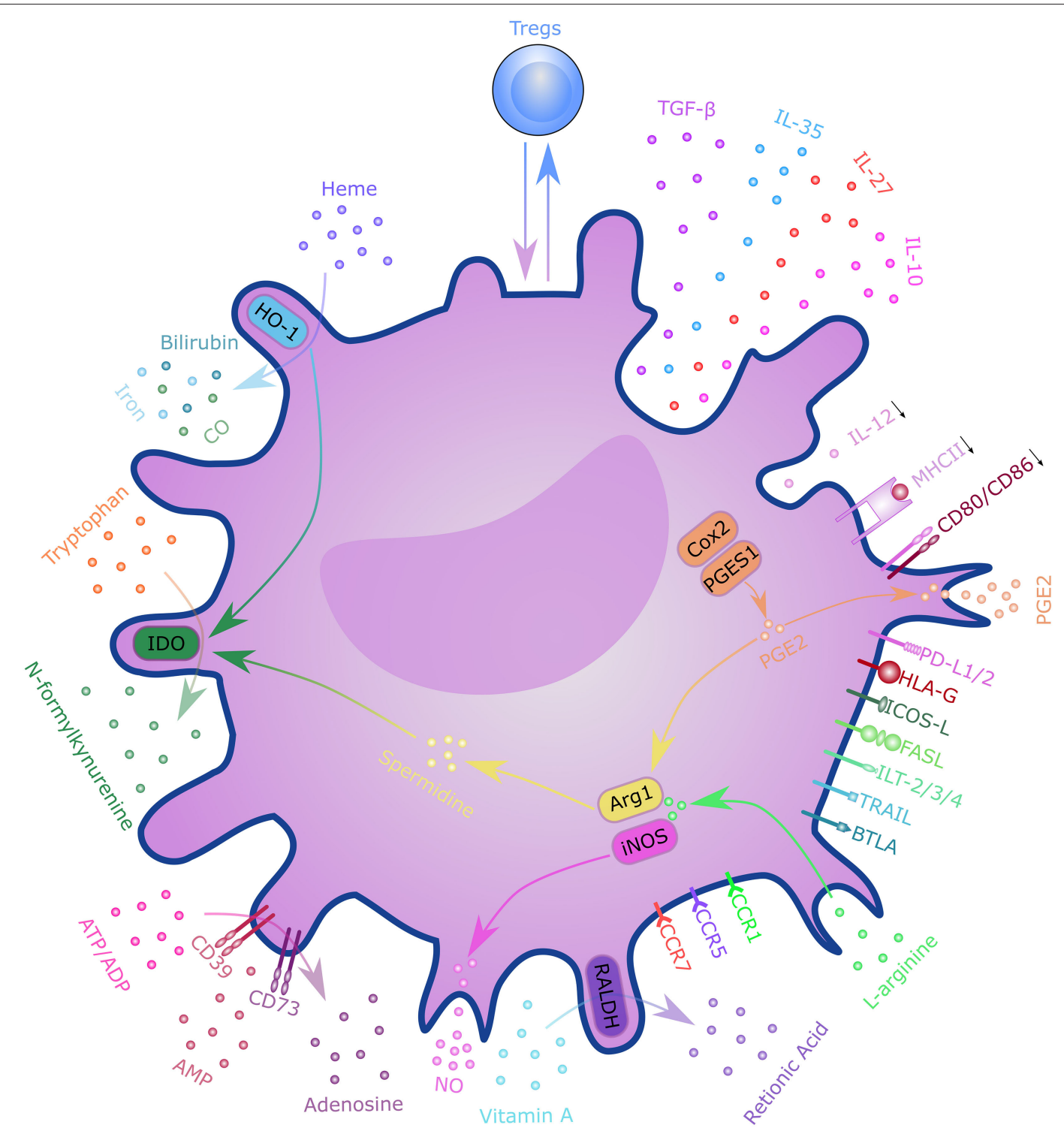

FIGURE 3 | Mechanisms of regulatory dendritic cells. DCregs exert a regulatory function through T cell anergy, T cell deletion, and regulatory T cell induction. These mechanisms involve direct cell-cell interactions through surface molecules, as well as through the immunosuppressive milieu via secretory factors. DCregs and Tregs interact with each other through a self-maintaining regulatory loop. DC, dendritic cell; PD-L1/2, programmed cell death ligand 1; ICOS-L, inducible T-cell costimulatory ligand; TGF- $\beta$, transforming growth factor $\beta$; HLA-G, human leukocyte antigen G; FasL, Fas ligand; ILT-2/3/4, immunoglobulin-like transcript-2/3/4; TRAlL, tumor necrosis factor-related apoptosis inducing ligand; BTLA, B- and T-lymphocyte attenuator; CCR7, C-C chemokine receptor 7; CXCR-4, C-X-C chemokine receptor type 4; IL, interleukin; RALDH, retinaldehyde dehydrogenases; NO, nitric oxide; ATP, adenosine triphosphate; ADP, adenosine diphosphate; AMP, adenosine monophosphate; IDO, indoleamine 2,3-dioxygenase; CO, carbon monoxide; HO-1, Heme oxygenase 1; Cox2, cyclooxygenase 2; PGES1, prostaglandin E synthase-1; ARG1, arginase 1; iNOS, inducible nitric oxide synthase; MHCII, major histocompatibility complex class II; PGE2, Prostaglandin E2; Tregs, regulatory T cells.

as an alternative combination to enhance tolerogenic properties and to minimize the risk of host sensitization. These studies have extensively investigated the safety and efficiency of donorand host-derived DCregs. Although donor-derived DCregs were shown to be capable of inducing transplant tolerance in vivo, the underlying mechanisms remain unclear. It is generally assumed that donor-derived DCregs mediate transplantation tolerance via the direct allorecognition pathway, leading to alloreactive $\mathrm{T}$ cell anergy, T cell deletion, or Treg induction. However, Divito et al. demonstrated that host DCs mediated the therapeutic effects of the infused donor-derived DCregs (115), which are likely to be rapidly killed by host NK cells or captured and reprocessed by host splenic DCs, which induce Tregs and graft tolerance. This notion was further supported by the finding that the deletion of host DCs abrogates the tolerogenic effects of donor-derived DCregs (116). 


\section{Ex vivo generated DCregs}

Nature pregenitors or PSCs from donor or host

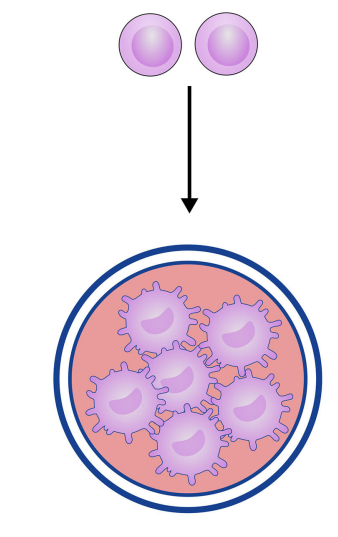

\section{In situ targeting of DCregs}
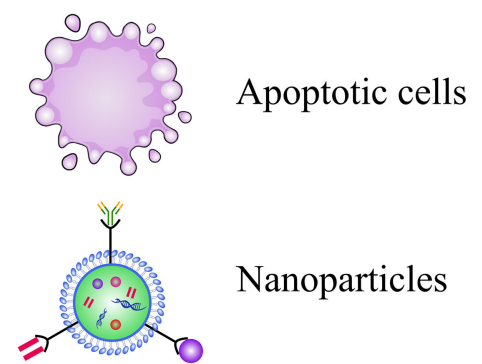

Nanoparticles

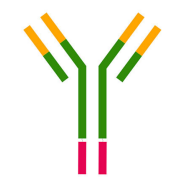

Chimeric antibodies

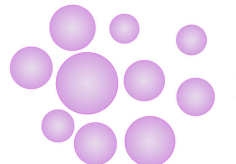

Exosomes

$\mathrm{GM}-\mathrm{CSF} \pm \mathrm{IL}-4 \pm \mathrm{PA}$

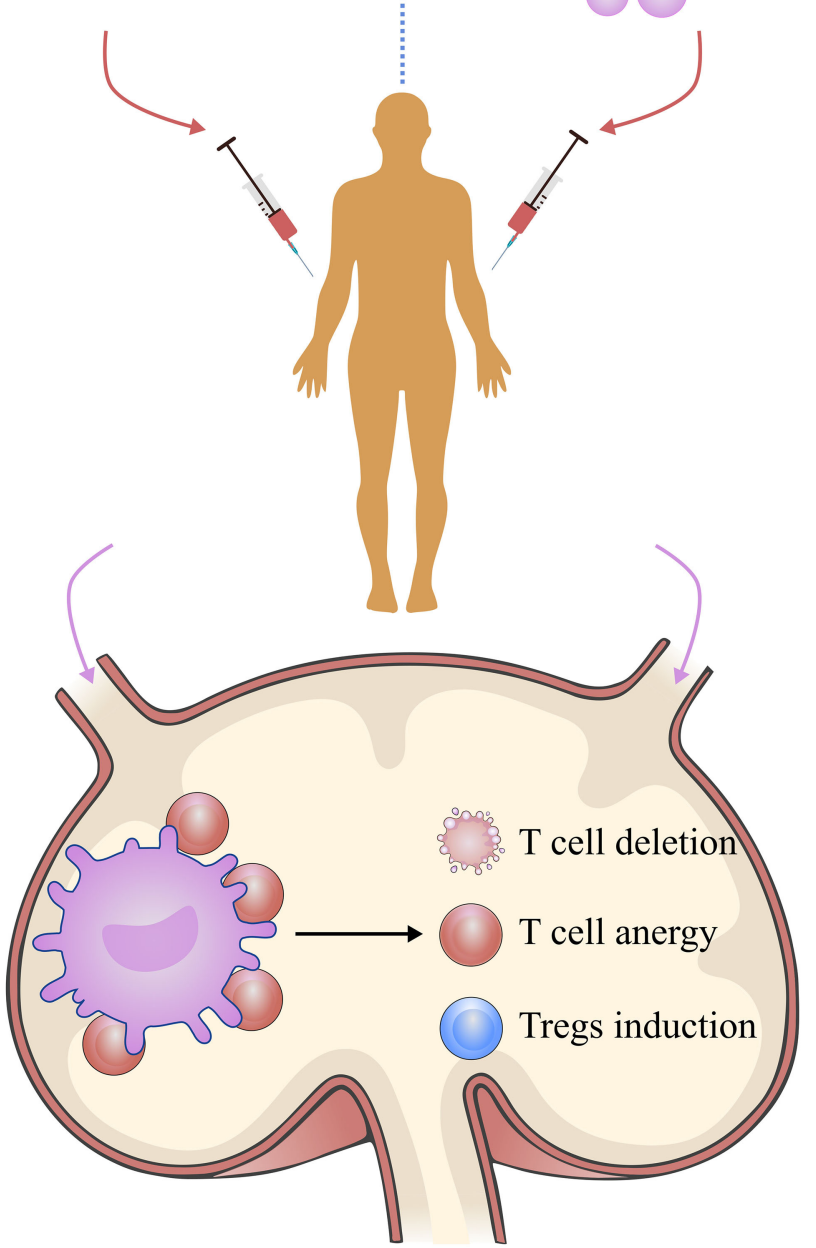

FIGURE 4 | Manipulation of regulatory dendritic cells to promote transplantation tolerance. DCreg-based therapy is a promising strategy for establishing permanent, donor-specific immune tolerance and minimizing or even obviating the use of immunosuppressive drugs in transplantation. Manipulation of DCregs can be done by in situ targeting or infusion of ex vivo-generated DCregs or mediating donor-specific tolerance via alloreactive $T$ cell anergy, $T$ cell deletion, and Treg induction 
FIGURE 4 | mechanisms. DCreg, regulatory dendritic cell; PSC, pluripotent stem cell; GM-CSF, granulocyte-macrophage colony-stimulating factor; IL-4, interleukin-4; PA, pharmacological agent; regulatory T cells.

Contrary to the accepted paradigm, donor-derived DCregs function as antigen-transporting cells rather than APCs to promote transplantation tolerance. Alternatively, host-derived DCregs, either pulsed or unpulsed with donor antigens, have also been used to regulate the alloreactive $\mathrm{T}$ cell response and promote transplantation tolerance $(117,118)$. Taner et al. showed that infusion with rapamycin-treated, alloantigenpulsed, host-derived DCregs 1 week before transplantation induced antigen-specific $\mathrm{T}$ cell regulation and prolonged graft survival (117). Segovia et al. reported that host-derived DCregs unpulsed with donor antigens, referred to as autologous DCs, when combined with suboptimal doses of immunosuppression, induced prolonged donor-specific allograft survival through tmem176b-dependent antigen cross-presentation (119). Moreover, host-derived DCregs were reportedly more efficient in prolonging cardiac allograft survival than donor-derived DCregs $(118,120)$. From the clinical perspective, host-derived DCregs appear to be more feasible. Host-derived DCregs can be generated in vitro whenever needed while donor-derived DCregs require collecting cells from donors several days prior to transplantation, which is infeasible in cases of deceased organ donation. DCregs using unpulsed, host-derived, immature DCs infused on the day of transplantation decrease the risk of host sensitization against donor antigens (118).

\section{IN SITU TARGETING OF DCregs}

The infusion of ex vivo-generated DCregs in transplantation to regulate the alloreactive $\mathrm{T}$ cell response and to promote transplantation tolerance was evident in experimental models and entered clinical studies $(10,121,122)$. However, there are some limitations to the clinical application of this approach, including the risk of host sensitization due to the presence of transferred allogeneic molecules; the risk of rematuration after in vivo fusion, which could promote alloimmunity rather than tolerance; donor-derived DCregs being unsuitable for deceased organ donation; donor-derived DCregs being quickly eliminated by host NK cells; and the decreased ability to migrate to secondary lymphoid organs to present donor antigens. In situ manipulation of DCs is an alternative approach to achieving donor-specific transplantation tolerance. This approach utilizes the in situ delivery of immunomodulatory factors targeting DC to regulate the alloreactive $\mathrm{T}$ cell response, thereby avoiding the drawbacks of ex vivo-generated DCregs, and demonstrates the feasibility of tolerance induction.

The clearance of apoptotic cells by DCs is usually immunologically silent and accompanied by TGF- $\beta$ and IL10 release (123). Following the phagocytosis of apoptotic cells, DCs begin to exhibit tolerogenic properties. Donor-derived apoptotic cells have been used to deliver both donor antigens and inhibitory signals simultaneously to host DCs to induce antigen-specific allograft tolerance (124). Engulfing of apoptotic DCs converted immature DCs into DCregs that were resistant to LPS-induced maturation and induced the differentiation of Foxp3+ Treg (125). Exosomes are nano-sized membrane-bound extracellular vesicles produced in the endosomal compartment of most eukaryotic cells $(126,127)$. The phenotype and function of exosomes depend on the origin and state of the cell. DC-derived exosomes may bear MHC molecules, costimulatory molecules, and antigens and function as antigen-presenting nanovesicles $(128,129)$. Recent research has revealed the role of DC-derived exosomes in allorecognition and transplantation immunity (130). The tolerogenic function of DC-derived exosomes was demonstrated in experimental transplantation models $(131,132)$. Exosomes from immature, donor-derived DCs induced donorspecific allograft tolerance. Host DCs engulfed these exosomes and presented intact, donor MHC antigens (allo-MHC crossdressing) and immunomodulatory molecules, such as IL-10, $\mathrm{PD}-\mathrm{L} 1$, and IDO, in what was considered to be the mechanism underlying microchimerism and tolerance induction $(130,133)$.

Nanoparticle-based drug delivery systems are a valuable tool in modulating DCs in situ by enabling the direct delivery of encapsulated antigens and immunomodulatory agents via cell-specific targeting in vivo, thus facilitating precise immune regulation to induce transplantation tolerance (134). The poly (lactic-co-glycolic acid) (PLGA) nanoparticles approved by The Food and Drug Administration are the most frequently used nanocarriers. Nanoparticles can also be engineered by coating monoclonal antibodies so that they target specific DC subsets $(135,136)$. Delivery to DCs can be achieved by targeting DC receptors, including CD11c, CD40, CD205, CD206, CD209, and Fc receptors. The encapsulated agents are protected from enzymatic and chemical degradation, act directly on the DCs, and are more efficient than methods of systemic administration, especially of toxic reagents. Nanoparticle delivery of mycophenolic acid upregulated PD-L1 expression on DCs, prolonged mouse skin allograft survival, and avoided the toxicity of soluble drug delivery (137). Maldonado et al. induced antigenspecific immunological tolerance using polymeric synthetic nanoparticles loaded with antigens and rapamycin, which resulted in suppression of $\mathrm{T}$ cell activation and an increase in regulatory cells (138). Clustered regularly interspaced short palindromic repeat (CRISPR)/CRISPR-associated protein 9 (Cas9) is emerging as a powerful tool for engineering the genome in diverse organisms. Zhang et al. encapsulated Cas9 mRNA (mCas9) and a guide RNA targeting CD40 (gCD40) with nanoparticles (139). mCas9/gCD40 was effectively delivered into DCs and disrupted CD40 signaling, significantly protecting grafts from acute rejection-mediated injury and prolonging graft survival. We also developed a novel siRNA delivery system with a poly-dA extension at the $5^{\prime}$-end of the siRNA sense strand that was stably incorporated into $1,3-\beta$-glucan (schizophyllan, SPG) (140). siRNAs silencing the CD40 gene were delivered into DCs 
through its receptor, Dectin-1, resulting in antigen-specific Treg generation and permanent murine cardiac allograft tolerance. Moreover, nanoparticles have also been used as integrating imaging moieties for monitoring allograft rejection to provide diagnostic and prognostic information as well as for quantifying the treatment efficacy in transplant recipients (134).

Antigen delivery to DCs in vivo using recombinant chimeric antibodies, produced by genetically modifying original monoclonal antibodies and chemically coupling them with peptide antigens, is another promising approach to achieving specific immunomodulation $(141,142)$. This approach enables the delivery of antigens to DCs under steady-state conditions and the induction of peripheral tolerance $(143,144)$. Reeves et al. have shown that APC-targeted proinsulin expression converted insulin-specific CD8 + T-cell priming to tolerance in autoimmune-prone NOD mice (145). Ettinger et al. achieved prolonged survival of transgenic mouse skin grafts by utilizing an antibody recognizing the CD205 receptor to deliver the immunodominant domain of type XVII collagen to host DCs without inflammatory stimuli (146).

\section{DCregs IN CLINICAL ORGAN TRANSPLANTATION}

In rodent and non-human primate transplantation studies, DCregs exhibited promising potential as a natural, well-tolerated, antigen-specific therapeutic strategy capable of promoting lasting transplantation tolerance. The clinical study of the safety and efficacy of DCregs in transplantations has lagged behind that of autoimmune diseases, including type-1 diabetes, rheumatoid arthritis, and Crohn's disease, which have reported early safety data (147). Recently, early-phase clinical trials of DCregs in living-donor renal and liver transplantations have begun both in Europe and the US $(10,148)$.

At the University of Nantes, investigators launched a phase I/II trial of unpulsed autologous DCregs in living-donor renal transplantation (clinicaltrials.gov identifier: NCT0225055). The autologous, monocyte-derived DCregs were generated in a low concentration of GM-CSF and infused into hosts 1 day before transplantation. The hosts also received background immunosuppression with prednisolone, mycophenolate mofetil, and tacrolimus. Recently, the first results and related good manufacturing practice protocols have been published $(149,150)$. At the University of Pittsburgh, a three-arm, dose-escalation, phase I clinical trial evaluating the safety and feasibility of donorderived DCreg using a single infusion 1 week prior to livingdonor renal transplantation, in combination with mycophenolate mofetil steroid and tacrolimus immunosuppression therapy, is currently underway (NCT0364265).

\section{REFERENCES}

1. Watt KDS, Pedersen RA, Kremers WK, Heimbach JK, Charlton MR. Evolution of causes and risk factors for mortality post-liver transplant: results of the NIDDK long-term follow-up study. Am J Transplant. (2010) 10:1420-7. doi: 10.1111/j.1600-6143.2010.03126.x
Given the unique immunological function of the liver, almost half of highly selected liver transplant recipients showed good tolerance even after complete weaning from immunosuppression (151, 152). DCreg-based therapy contributing to antigen-specific tolerance induction may facilitate minimizing immunosuppression and early weaning after liver transplantation. At the University of Pittsburgh, Angus et al. has initiated two phase I/II trials to investigate the safety and efficacy of a single infusion of donor-derived DCreg 1 week before transplantation (NCT03164265) and 1 week before immunosuppression weaning (NCT04208919), respectively, in living donor liver transplant recipients. The donor monocyte-derived DCregs were generated in the presence of IL-10 and Vitamin D3 (153), and the hosts were slowly weaned off immunosuppression after meeting specific criteria.

\section{CONCLUDING REMARKS}

Dendritic cells are central instigators and regulators of transplantation immunity and are critical in the balance between allograft rejection and tolerance. Extensive studies focusing on the development, phenotype, and function of DCs have provided important insights into the mechanisms underlying tolerance induction. DCregs comprise a heterogeneous population of immature or semi-mature DCs which expressed low levels of MHC, costimulatory molecules, and altered cytokine production and mediated donor-specific tolerance through alloreactive $\mathrm{T}$ cell anergy, $\mathrm{T}$ cell deletion, and Treg induction. DCreg-based therapy, by in situ targeting or infusion of ex vivo-generated DCregs represents an emerging approach to preventing rejection and promoting donor-specific tolerance. Further studies are required to explore the translation of DCregs into clinical transplantation to induce tolerance and improve allograft acceptance.

\section{AUTHOR CONTRIBUTIONS}

WQ and W-ZG did the literature search and wrote the review. X-KL revised and approved the final version of the review. All authors contributed to the article and approved the submitted version.

\section{FUNDING}

This work was supported in part by research grants from the National Center for Child Health and Development (3020), the Ministry of Education, Culture, Sports, Science and Technology of Japan (Nos. 17H04277, 18F17794, 19K18045), and Science and Technology Innovation Talents in Henan Universities (No. 19HASTIT003).

2. Ojo AO, Held PJ, Port FK, Wolfe RA, Leichtman AB, Young EW, et al. Chronic renal failure after transplantation of a nonrenal organ. $N$ Engl J Med. (2003) 349:931-40. doi: 10.1056/NEJMoa021744

3. Valenzuela NM, Reed EF. Antibody-mediated rejection across solid organ transplants: manifestations, mechanisms, and therapies. J Clin Invest. (2017) 127:2492-504. doi: 10.1172/JCI90597 
4. Wood KJ, Goto R. Mechanisms of rejection: current perspectives. Transplantation. (2012) 93:1-10. doi: 10.1097/TP.0b013e31823cab44

5. Kwun J, Knechtle SJ. Overcoming chronic rejection-can it B? Transplantation. (2009) 88:955-61. doi: 10.1097/TP.0b013e3181b96646

6. Long E, Wood KJ. Regulatory $\mathrm{T}$ cells in transplantation: transferring mouse studies to the clinic. Transplantation. (2009) 88:1050-6. doi: 10.1097/TP.0b013e3181bb7913

7. Roncarolo MG, Gregori S, Bacchetta R, Battaglia M. Tr1 cells and the counter-regulation of immunity: natural mechanisms and therapeutic applications. Curr Top Microbiol Immunol. (2014) 380:39-68. doi: 10.1007/978-3-662-43492-5_3

8. Sicard A, Koenig A, Morelon E, Defrance T, Thaunat O. Cell therapy to induce allograft tolerance: time to switch to plan B? Front Immunol. (2015) 6:149. doi: 10.3389/fimmu.2015.00149

9. Broichhausen C, Riquelme P, Geissler EK, Hutchinson JA. Regulatory macrophages as therapeutic targets and therapeutic agents in solid organ transplantation. Curr Opin Organ Transplant. (2012) 17:33242. doi: 10.1097/MOT.0b013e328355a979

10. Thomson AW, Metes DM, Ezzelarab MB, Raïch-Regué D. Regulatory dendritic cells for human organ transplantation. Transplant Rev. (2019) 33:130-6. doi: 10.1016/j.trre.2019.05.001

11. Wood KJ, Bushell A, Hester J. Regulatory immune cells in transplantation. Nat Rev Immunol. (2012) 12:417-30. doi: 10.1038/nri3227

12. Papp G, Boros P, Nakken B, Szodoray P, Zeher M. Regulatory immune cells and functions in autoimmunity and transplantation immunology. Autoimmun Rev. (2017) 16:435-44. doi: 10.1016/j.autrev.2017.03.011

13. Banchereau J, Steinman RM. Dendritic cells and the control of immunity. Nature. (1998) 392:245-52. doi: 10.1038/32588

14. Steinman RM, Hawiger D, Nussenzweig MC. Tolerogenic dendritic cells. Annu Rev Immunol. (2003) 21:685711. doi: 10.1146/annurev.immunol.21.120601.141040

15. Merad M, Sathe P, Helft J, Miller J, Mortha A. The dendritic cell lineage: ontogeny and function of dendritic cells and their subsets in the steady state and the inflamed setting. Annu Rev Immunol. (2013) 31:563604. doi: 10.1146/annurev-immunol-020711-074950

16. Eisenbarth SC. Dendritic cell subsets in $\mathrm{T}$ cell programming: location dictates function. Nat Rev Immunol. (2018) 19:89103. doi: 10.1038/s41577-018-0088-1

17. Guermonprez P, Valladeau J, Zitvogel L, Théry C, Amigorena S. Antigen presentation and T cell stimulation by dendritic cells. Annu Rev Immunol. (2002) 20:621-67. doi: 10.1146/annurev.immunol.20.100301.064828

18. Reis e Sousa C. Dendritic cells in a mature age. Nat Rev Immunol. (2006) 6:476-83. doi: $10.1038 /$ nri1845

19. Mildner A, Jung S. Development and function of dendritic cell subsets. Immunity. (2014) 40:642-56. doi: 10.1016/j.immuni.2014.04.016

20. Birnberg T, Bar-On L, Sapoznikov A, Caton ML, Cervantes-Barragán L, Makia D, et al. Lack of conventional dendritic cells is compatible with normal development and $\mathrm{T}$ cell homeostasis, but causes myeloid proliferative syndrome. Immunity. (2008) 29:986-97. doi: 10.1016/j.immuni.2008.10.012

21. Jung S, Unutmaz D, Wong P, Sano G-I, De los Santos K, Sparwasser $\mathrm{T}$, et al. In vivo depletion of $\mathrm{CD} 11 \mathrm{c}+$ dendritic cells abrogates priming of $\mathrm{CD} 8+\mathrm{T}$ cells by exogenous cell-associated antigens. Immunity. (2002) 17:211-20. doi: 10.1016/S1074-7613(02)00 365-5

22. den Haan JM, Lehar SM, Bevan MJ. CD8(+) but not CD8(-) dendritic cells cross-prime cytotoxic T cells in vivo. J Exp Med. (2000) 192:168596. doi: 10.1084/jem.192.12.1685

23. Dudziak D, Kamphorst AO, Heidkamp GF, Buchholz VR, Trumpfheller C, Yamazaki S, et al. Differential antigen processing by dendritic cell subsets in vivo. Science. (2007) 315:107-11. doi: 10.1126/science.1136080

24. Lewis KL, Caton ML, Bogunovic M, Greter M, Grajkowska LT, Ng D, et al. Notch2 receptor signaling controls functional differentiation of dendritic cells in the spleen and intestine. Immunity. (2011) 35:780-91. doi: 10.1016/j.immuni.2011.0 8.013

25. Nakano H, Yanagita M, Gunn MD. CD11c(+)B220(+)Gr-1(+) cells in mouse lymph nodes and spleen display characteristics of plasmacytoid dendritic cells. J Exp Med. (2001) 194:1171-8. doi: 10.1084/jem.194.8.1171
26. Honda K, Yanai H, Negishi H, Asagiri M, Sato M, Mizutani T, et al. IRF-7 is the master regulator of type-I interferon-dependent immune responses. Nature. (2005) 434:772-7. doi: 10.1038/nature03464

27. Colonna M, Trinchieri G, Liu YJ. Plasmacytoid dendritic cells in immunity. Nat Immunol. (2004) 5:1219-26. doi: 10.1038/nil141

28. Matta BM, Castellaneta A, Thomson AW. Tolerogenic plasmacytoid DC. Eur J Immunol. (2010) 40:2667-76. doi: 10.1002/eji.201040839

29. Serbina NV, Salazar-Mather TP, Biron CA, Kuziel WA, Pamer EG. TNF/iNOS-producing dendritic cells mediate innate immune defense against bacterial infection. Immunity. (2003) 19:59-70. doi: 10.1016/S1074-7613(03)00171-7

30. Crozat K, Guiton R, Guilliams M, Henri S, Baranek T, Schwartz-Cornil I, et al. Comparative genomics as a tool to reveal functional equivalences between human and mouse dendritic cell subsets. Immunol Rev. (2010) 234:177-98. doi: 10.1111/j.0105-2896.2009.00868.x

31. Guilliams M, Ginhoux F, Jakubzick C, Naik SH, Onai N, Schraml BU, et al. Dendritic cells, monocytes and macrophages: a unified nomenclature based on ontogeny. Nat Rev Immunol. (2014) 14:571-8. doi: 10.1038/nri3712

32. Clayton K, Vallejo AF, Davies J, Sirvent S, Polak ME. Langerhans cells-programmed by the epidermis. Front Immunol. (2017) 8:1676. doi: 10.3389/fimmu.2017.01676

33. Hoeffel G, Wang Y, Greter M, See P, Teo P, Malleret B, et al. Adult Langerhans cells derive predominantly from embryonic fetal liver monocytes with a minor contribution of yolk sac-derived macrophages. J Exp Med. (2012) 209:1167-81. doi: 10.1084/jem.20120340

34. Merad M, Manz MG, Karsunky H, Wagers A, Peters W, Charo I, et al. Langerhans cells renew in the skin throughout life under steady-state conditions. Nat Immunol. (2002) 3:1135-41. doi: 10.1038/ni852

35. Ginhoux F, Tacke F, Angeli V, Bogunovic M, Loubeau M, Dai X-M, et al. Langerhans cells arise from monocytes in vivo. Nat Immunol. (2006) 7:265-73. doi: 10.1038/ni1307

36. Ginhoux F, Liu K, Helft J, Bogunovic M, Greter M, Hashimoto D, et al. The origin and development of nonlymphoid tissue CD103+ DCs. J Exp Med. (2009) 206:3115-30. doi: 10.1084/jem.20091756

37. Wang Y, Szretter KJ, Vermi W, Gilfillan S, Rossini C, Cella M, et al. IL-34 is a tissue-restricted ligand of CSF1R required for the development of Langerhans cells and microglia. Nat Immunol. (2012) 13:753-60. doi: $10.1038 /$ ni.2360

38. Coquerelle C, Moser M. DC subsets in positive and negative regulation of immunity. Immunol Rev. (2010) 234:31734. doi: 10.1111/j.0105-2896.2009.00887.x

39. Steinman RM, Nussenzweig MC. Avoiding horror autotoxicus: the importance of dendritic cells in peripheral T cell tolerance. Proc Natl Acad Sci USA. (2002) 99:351-8. doi: 10.1073/pnas.231606698

40. Merad M, Manz MG. Dendritic cell homeostasis. Blood. (2009) 113:341827. doi: 10.1182/blood-2008-12-180646

41. Poltorak MP, Schraml BU. Fate mapping of dendritic cells. Front Immunol. (2015) 6:199. doi: 10.3389/fimmu.2015.00199

42. Fogg DK, Sibon C, Miled C, Jung S, Aucouturier P, Littman DR, et al. A clonogenic bone marrow progenitor specific for macrophages and dendritic cells. Science. (2006) 311:83-7. doi: 10.1126/science.1117729

43. Hettinger J, Richards DM, Hansson J, Barra MM, Joschko AC, Krijgsveld J, et al. Origin of monocytes and macrophages in a committed progenitor. Nat Immunol. (2013) 14:821-30. doi: 10.1038/ni.2638

44. Shortman K, Naik SH. Steady-state and inflammatory dendritic-cell development. Nat Rev Immunol. (2007) 7:19-30. doi: 10.1038/nri1996

45. Mildner A, Yona S, Jung S. A close encounter of the third kind: monocyte-derived cells. Adv Immunol. (2013) 120:69103. doi: 10.1016/B978-0-12-417028-5.00003-X

46. Haniffa M, Collin M, Ginhoux F. Ontogeny and functional specialization of dendritic cells in human and mouse. Adv Immunol. (2013) 120:149. doi: 10.1016/B978-0-12-417028-5.00001-6

47. Naik SH, Sathe P, Park HY, Metcalf D, Proietto AI, Dakic A, et al. Development of plasmacytoid and conventional dendritic cell subtypes from single precursor cells derived in vitro and in vivo. Nat Immunol. (2007) 8:1217-26. doi: 10.1038/ni1522

48. Onai N, Obata-Onai A, Schmid MA, Ohteki T, Jarrossay D, Manz MG. Identification of clonogenic common Flt3+M-CSFR+ plasmacytoid and 
conventional dendritic cell progenitors in mouse bone marrow. Nat Immunol. (2007) 8:1207-16. doi: 10.1038/ni1518

49. Reizis B. Plasmacytoid dendritic cells: development, regulation, and function. Immunity. (2019) 50:37-50. doi: 10.1016/j.immuni.2018.12.027

50. Shortman K, Sathe P, Vremec D, Naik S, O'Keeffe M. Plasmacytoid dendritic cell development. Adv Immunol. (2013) 120:105-26. doi: 10.1016/B978-0-12-417028-5.00004-1

51. Liu K, Victora GD, Schwickert TA, Guermonprez P, Meredith MM, Yao K, et al. In vivo analysis of dendritic cell development and homeostasis. Science. (2009) 324:392-7. doi: 10.1126/science.1170540

52. Liu K, Waskow C, Liu X, Yao K, Hoh J, Nussenzweig M. Origin of dendritic cells in peripheral lymphoid organs of mice. Nat Immunol. (2007) 8:57883. doi: $10.1038 /$ ni1462

53. Schulz C, Gomez Perdiguero E, Chorro L, Szabo-Rogers H, Cagnard N, Kierdorf $\mathrm{K}$, et al. A lineage of myeloid cells independent of Myb and hematopoietic stem cells. Science. (2012) 336:86-90. doi: 10.1126/science.1219179

54. Ferrer IR, West HC, Henderson S, Ushakov DS, Sousa PS e, Strid $\mathrm{J}$, et al. A wave of monocytes is recruited to replenish the longterm Langerhans cell network after immune injury. Sci Immunol. (2019) 4:eaax8704. doi: 10.1126/sciimmunol.aax8704

55. Tang D, Kang R, Coyne CB, Zeh HJ, Lotze MT. PAMPs and DAMPs: signal 0s that spur autophagy and immunity. Immunol Rev. (2012) 249:15875. doi: 10.1111/j.1600-065X.2012.01146.x

56. Matzinger P. The danger model: a renewed sense of self. Science. (2002) 296:301-5. doi: 10.1126/science.1071059

57. Iwasaki A, Medzhitov R. Regulation of adaptive immunity by the innate immune system. Science. (2010) 327:291-5. doi: 10.1126/science.1183021

58. Meylan E, Tschopp J. Toll-like receptors and RNA helicases: two parallel ways to trigger antiviral responses. Mol Cell. (2006) 22:5619. doi: 10.1016/j.molcel.2006.05.012

59. Re F, Strominger JL. Heterogeneity of TLR-induced responses in dendritic cells: from innate to adaptive immunity. Immunobiology. (2004) 209:1918. doi: 10.1016/j.imbio.2004.03.005

60. Steinman RM, Banchereau J. Taking dendritic cells into medicine. Nature. (2007) 449:419-26. doi: 10.1038/nature06175

61. Penna G, Vulcano M, Sozzani S, Adorini L. Differential migration behavior and chemokine production by myeloid and plasmacytoid dendritic cells. Hum Immunol. (2002) 63:1164-71. doi: 10.1016/S0198-8859(02)00755-3

62. Colvin BL, Matta BM, Thomson AW. Dendritic cells and chemokinedirected migration in transplantation: where are we headed? Clin Lab Med. (2008) 28:375-84. doi: 10.1016/j.cll.2008.07.003

63. Miller MJ, Wei SH, Parker I, Cahalan MD. Two-photon imaging of lymphocyte motility and antigen response in intact lymph node. Science. (2002) 296:1869-73. doi: 10.1126/science.1070051

64. Bousso P, Robey E. Dynamics of CD8 $+\mathrm{T}$ cell priming by dendritic cells in intact lymph nodes. Nat Immunol. (2003) 4:579-85. doi: 10.1038/ni928

65. Benvenuti F. The dendritic cell synapse: a life dedicated to $\mathrm{T}$ cell activation. Front Immunol. (2016) 7:70. doi: 10.3389/fimmu.2016.00070

66. Priyadharshini B, Greiner DL, Brehm MA. T cell activation and transplantation tolerance. Transplant Rev (Orlando). (2012) 26:21222. doi: 10.1016/j.trre.2011.09.002

67. Malissen B, Grégoire C, Malissen M, Roncagalli R. Integrative biology of T cell activation. Nat Immunol. (2014) 15:790-7. doi: 10.1038/ni.2959

68. Benichou G, Yamada Y, Yun S-H, Lin C, Fray M, Tocco G. Immune recognition and rejection of allogeneic skin grafts. Immunotherapy. (2011) 3:757-70. doi: 10.2217/imt.11.2

69. Illigens BM, Yamada A, Fedoseyeva EV, Anosova N, Boisgerault F, Valujskikh A, et al. The relative contribution of direct and indirect antigen recognition pathways to the alloresponse and graft rejection depends upon the nature of the transplant. Hum Immunol. (2002) 63:91225. doi: 10.1016/S0198-8859(02)00449-4

70. Auchincloss H, Lee R, Shea S, Markowitz JS, Grusby MJ, Glimcher LH. The role of "indirect" recognition in initiating rejection of skin grafts from major histocompatibility complex class II-deficient mice. Proc Natl Acad Sci USA. (1993) 90:3373-7. doi: 10.1073/pnas.90.8.3373

71. Diebold SS. Determination of T-cell fate by dendritic cells. Immunol Cell Biol. (2008) 86:389-97. doi: 10.1038/icb.2008.26
72. Schwartz RH. T cell anergy. Annu Rev Immunol. (2003) 21:30534. doi: 10.1146/annurev.immunol.21.120601.141110

73. Koenen HJ, Joosten I. Blockade of CD86 and CD40 induces alloantigen-specific immunoregulatory $\mathrm{T}$ cells that remain anergic even after reversal of hyporesponsiveness. Blood. (2000) 95:3153-61. doi: 10.1182/blood.V95.10.3153

74. Bishop KD, Harris JE, Mordes JP, Greiner DL, Rossini AA, Czech MP, et al. Depletion of the programmed death-1 receptor completely reverses established clonal anergy in CD4+ $\mathrm{T}$ lymphocytes via an interleukin-2-dependent mechanism. Cell Immunol. (2009) 256:86-91. doi: 10.1016/j.cellimm.2009.01.008

75. Greenwald RJ, Boussiotis VA, Lorsbach RB, Abbas AK, Sharpe AH. CTLA-4 regulates induction of anergy in vivo. Immunity. (2001) 14:14555. doi: 10.1016/S1074-7613(01)00097-8

76. Tuettenberg A, Huter E, Hubo M, Horn J, Knop J, Grimbacher B, et al. The role of ICOS in directing T cell responses: ICOS-dependent induction of T cell anergy by tolerogenic dendritic cells. J Immunol. (2009) 182:334956. doi: 10.4049/jimmunol.0802733

77. Chauveau C, Rémy S, Royer PJ, Hill M, Tanguy-Royer S, Hubert F-X, et al. Heme oxygenase-1 expression inhibits dendritic cell maturation and proinflammatory function but conserves IL-10 expression. Blood. (2005) 106:1694-702. doi: 10.1182/blood-2005-02-0494

78. Moreau A, Hill M, Thébault P, Deschamps JY, Chiffoleau E, Chauveau $\mathrm{C}$, et al. Tolerogenic dendritic cells actively inhibit $\mathrm{T}$ cells through heme oxygenase-1 in rodents and in nonhuman primates. FASEB J. (2009) 23:3070-7. doi: 10.1096/fj.08-128173

79. Zhao Y, Jia Y, Wang L, Chen S, Huang X, Xu B, et al. Upregulation of heme oxygenase-1 endues immature dendritic cells with more potent and durable immunoregulatory properties and promotes engraftment in a stringent mouse cardiac allotransplant model. Front Immunol. (2018) 9:1515. doi: 10.3389/fimmu.2018.01515

80. Blancou P, Anegon I. Editorial: heme oxygenase-1 and dendritic cells: what else? J Leukoc Biol. (2010) 87:185-7. doi: 10.1189/jlb.0909636

81. Hasegawa $\mathrm{H}$, Matsumoto T. Mechanisms of tolerance induction by dendritic cells in vivo. Front Immunol. (2018) 9:350. doi: 10.3389/fimmu.2018.00350

82. Lu L, Qian S, Hershberger PA, Rudert WA, Lynch DH, Thomson AW. Fas ligand (CD95L) and B7 expression on dendritic cells provide counter-regulatory signals for $\mathrm{T}$ cell survival and proliferation. J Immunol. (1997) 158:5676-84.

83. Mellor AL, Baban B, Chandler P, Marshall B, Jhaver K, Hansen A, et al. Cutting edge: induced indoleamine 2,3 dioxygenase expression in dendritic cell subsets suppresses T cell clonal expansion. J Immunol. (2003) 171:16525. doi: 10.4049/jimmunol.171.4.1652

84. Min W-P, Zhou D, Ichim TE, Strejan GH, Xia X, Yang J, et al. Inhibitory feedback loop between tolerogenic dendritic cells and regulatory $\mathrm{T}$ cells in transplant tolerance. J Immunol. (2003) 170:1304-12. doi: 10.4049/jimmunol.170.3.1304

85. Sabado RL, Balan S, Bhardwaj N. Dendritic cell-based immunotherapy. Cell Res. (2017) 27:74-95. doi: 10.1038/cr.2016.157

86. Hackstein H, Thomson AW. Dendritic cells: emerging pharmacological targets of immunosuppressive drugs. Nat Rev Immunol. (2004) 4:2434. doi: $10.1038 /$ nri1256

87. Naranjo-Gómez M, Raïch-Regué D, Oñate C, Grau-López L, Ramo-Tello C, Pujol-Borrell R, et al. Comparative study of clinical grade human tolerogenic dendritic cells. J Transl Med. (2011) 9:89. doi: 10.1186/1479-5876-9-89

88. Yamano T, Watanabe S, Hasegawa H, Suzuki T, Abe R, Tahara H, et al. Ex vivo-expanded DCs induce donor-specific central and peripheral tolerance and prolong the acceptance of donor skin grafts. Blood. (2011) 117:26408. doi: 10.1182/blood-2010-07-293860

89. Eto M, Hackstein H, Kaneko K, Nomoto K, Thomson AW. Promotion of skin graft tolerance across MHC barriers by mobilization of dendritic cells in donor hemopoietic cell infusions. J Immunol. (2002) 169:23906. doi: 10.4049/jimmunol.169.5.2390

90. Penna G, Adorini L. 1 Alpha,25-dihydroxyvitamin D3 inhibits differentiation, maturation, activation, and survival of dendritic cells leading to impaired alloreactive $\mathrm{T}$ cell activation. $J$ Immunol. (2000) 164:2405-11. doi: 10.4049/jimmunol.164.5. 2405 
91. Turnquist HR, Raimondi G, Zahorchak AF, Fischer RT, Wang Z, Thomson AW. Rapamycin-conditioned dendritic cells are poor stimulators of allogeneic CD4+ T cells, but enrich for antigen-specific Foxp3 + T regulatory cells and promote organ transplant tolerance. J Immunol. (2007) 178:701831. doi: 10.4049/jimmunol.178.11.7018

92. Steinbrink K, Wölfl M, Jonuleit H, Knop J, Enk AH. Induction of tolerance by IL-10-treated dendritic cells. J Immunol. (1997) 159:4772-80.

93. Buelens C, Verhasselt V, De Groote D, Thielemans K, Goldman M, Willems F. Human dendritic cell responses to lipopolysaccharide and CD40 ligation are differentially regulated by interleukin-10. Eur J Immunol. (1997) 27:1848-52. doi: 10.1002/eji.1830270805

94. Steinbrink K, Graulich E, Kubsch S, Knop J, Enk AH. CD4(+) and CD8(+) anergic T cells induced by interleukin-10-treated human dendritic cells display antigen-specific suppressor activity. Blood. (2002) 99:246876. doi: 10.1182/blood.V99.7.2468

95. Boks MA, Kager-Groenland JR, Haasjes MSP, Zwaginga JJ, van Ham SM, ten Brinke A. IL-10-generated tolerogenic dendritic cells are optimal for functional regulatory $\mathrm{T}$ cell induction-a comparative study of human clinical-applicable DC. Clin Immunol. (2012) 142:332-42. doi: 10.1016/j.clim.2011.11.011

96. Gregori S, Tomasoni D, Pacciani V, Scirpoli M, Battaglia M, Magnani $\mathrm{CF}$, et al. Differentiation of type $1 \mathrm{~T}$ regulatory cells $(\operatorname{Tr} 1)$ by tolerogenic DC-10 requires the IL-10-dependent ILT4/HLA-G pathway. Blood. (2010) 116:935-44. doi: 10.1182/blood-2009-07-234872

97. Unger WWJ, Laban S, Kleijwegt FS, van der Slik AR, Roep BO. Induction of Treg by monocyte-derived DC modulated by vitamin D3 or dexamethasone: differential role for PD-L1. Eur J Immunol. (2009) 39:314759. doi: 10.1002/eji.200839103

98. Grohmann U, Volpi C, Fallarino F, Bozza S, Bianchi R, Vacca C, et al. Reverse signaling through GITR ligand enables dexamethasone to activate IDO in allergy. Nat Med. (2007) 13:579-86. doi: 10.1038/nm1563

99. Kleijwegt FS, Laban S, Duinkerken G, Joosten AM, Koeleman BPC, Nikolic $\mathrm{T}$, et al. Transfer of regulatory properties from tolerogenic to proinflammatory dendritic cells via induced autoreactive regulatory $\mathrm{T}$ cells. J Immunol. (2011) 187:6357-64. doi: 10.4049/jimmunol.1101638

100. Nikolic T, Roep BO. Regulatory multitasking of tolerogenic dendritic cells - lessons taken from vitamin d3-treated tolerogenic dendritic cells. Front Immunol. (2013) 4:113. doi: 10.3389/fimmu.2013.00113

101. Anderson AE, Sayers BL, Haniffa MA, Swan DJ, Diboll J, Wang X$\mathrm{N}$, et al. Differential regulation of naïve and memory CD4+ $\mathrm{T}$ cells by alternatively activated dendritic cells. J Leukoc Biol. (2008) 84:12433. doi: 10.1189/jlb.1107744

102. Anderson AE, Swan DJ, Sayers BL, Harry RA, Patterson AM, von Delwig A, et al. LPS activation is required for migratory activity and antigen presentation by tolerogenic dendritic cells. J Leukoc Biol. (2009) 85:24350. doi: 10.1189/jlb.0608374

103. Sordi V, Bianchi G, Buracchi C, Mercalli A, Marchesi F, D'Amico $\mathrm{G}$, et al. Differential effects of immunosuppressive drugs on chemokine receptor CCR7 in human monocyte-derived dendritic cells: selective upregulation by rapamycin. Transplantation. (2006) 82:826-34. doi: 10.1097/01.tp.0000235433.03554.4f

104. Humbert J-M, Halary F. Viral and non-viral methods to genetically modify dendritic cells. Curr Gene Ther. (2012) 12:127-36. doi: 10.2174/156652312800099580

105. Li R, Zheng X, Popov I, Zhang X, Wang H, Suzuki M, et al. Gene silencing of IL-12 in dendritic cells inhibits autoimmune arthritis. J Transl Med. (2012) 10:19. doi: 10.1186/1479-5876-10-19

106. Liang X, Lu L, Chen Z, Vickers T, Zhang H, Fung JJ, et al. Administration of dendritic cells transduced with antisense oligodeoxyribonucleotides targeting CD80 or CD86 prolongs allograft survival. Transplantation. (2003) 76:721-729. doi: $10.1097 / 01 . T P .0000076470 .354$ 04.49

107. Giannoukakis N, Bonham CA, Qian S, Chen Z, Peng L, Harnaha J, et al. Prolongation of cardiac allograft survival using dendritic cells treated with NF-kB decoy oligodeoxyribonucleotides. Mol Ther. (2000) 1:4307. doi: $10.1006 / \mathrm{mthe} .2000 .0060$

108. Dong Z, Chen Y, Peng Y, Wang F, Yang Z, Huang G, et al. Concurrent CCR7 overexpression and RelB knockdown in immature dendritic cells induces immune tolerance and improves skin-graft survival in a murine model. Cell Physiol Biochem. (2017) 42:455-68. doi: 10.1159/000477593

109. Cai S, Hou J, Fujino M, Zhang Q, Ichimaru N, Takahara S, et al. iPSCderived regulatory dendritic cells inhibit allograft rejection by generating alloantigen-specific regulatory T cells. Stem Cell Reports. (2017) 8:117489. doi: 10.1016/j.stemcr.2017.03.020

110. Senju S, Hirata S, Motomura Y, Fukuma D, Matsunaga Y, Fukushima S, et al. Pluripotent stem cells as source of dendritic cells for immune therapy. Int J Hematol. (2010) 91:392-400. doi: 10.1007/s12185-010-0520-1

111. Li Y, Liu M, Yang ST. Dendritic cells derived from pluripotent stem cells: potential of large scale production. World J Stem Cells. (2014) 6:110. doi: 10.4252/wjsc.v6.i1.1

112. Zeng J, Wu C, Wang S. Antigenically modified human pluripotent stem cells generate antigen-presenting dendritic cells. Sci Rep. (2015) 5:15262. doi: 10.1038/srep15262

113. Fu F, Li Y, Qian S, Lu L, Chambers F, Starzl TE, et al. Costimulatory molecule-deficient dendritic cell progenitors (MHC Class II+, CD80dim, CD86-) prolong cardiac allograft survival in nonimmunosuppressed recipients. Transplantation. (1996) 62:659-65. doi: 10.1097/00007890-199609150-00021

114. Rastellini C, Lu L, Ricordi C, Starzl TE, Rao AS, Thomson AW. Granulocyte/macrophage colony-stimulating factor-stimulated hepatic dendritic cell progenitors prolong pancreatic islet allograft survival. Transplantation. (1995) 60:1366-70.

115. Divito SJ, Wang Z, Shufesky WJ, Liu Q, Tkacheva OA, Montecalvo A, et al. Endogenous dendritic cells mediate the effects of intravenously injected therapeutic immunosuppressive dendritic cells in transplantation. Blood. (2010) 116:2694-705. doi: 10.1182/blood-2009-10-251058

116. Wang Z, Divito SJ, Shufesky WJ, Sumpter T, Wang H, Tkacheva OA, et al. Dendritic cell therapies in transplantation revisited: deletion of recipient DCs deters the effect of therapeutic DCs. Am J Transplant. (2012) 12:1398408. doi: 10.1111/j.1600-6143.2012.04060.x

117. Taner T, Hackstein H, Wang Z, Morelli AE, Thomson AW. Rapamycintreated, alloantigen-pulsed host dendritic cells induce Ag-specific $\mathrm{T}$ cell regulation and prolong graft survival. Am J Transplant. (2005) 5:22836. doi: 10.1046/j.1600-6143.2004.00673.x

118. Pêche H, Trinité B, Martinet B, Cuturi MC. Prolongation of heart allograft survival by immature dendritic cells generated from recipient type bone marrow progenitors. Am J Transplant. (2005) 5:255-67. doi: 10.1111/j.1600-6143.2004.00683.x

119. Segovia M, Louvet C, Charnet P, Savina A, Tilly G, Gautreau L, et al. Autologous dendritic cells prolong allograft survival through Tmem176bdependent antigen cross-presentation. Am J Transplant. (2014) 14:102131. doi: 10.1111/ajt.12708

120. Bériou G, Pêche H, Guillonneau C, Merieau E, Cuturi M-C. Donorspecific allograft tolerance by administration of recipient-derived immature dendritic cells and suboptimal immunosuppression. Transplantation. (2005) 79:969-72. doi: 10.1097/01.TP.0000158277.50073.35

121. Marín E, Cuturi MC, Moreau A. Tolerogenic dendritic cells in solid organ transplantation: where do we stand? Front Immunol. (2018) 9:274. doi: 10.3389/fimmu.2018.00274

122. Obregon C, Kumar R, Pascual MA, Vassalli G, Golshayan D. Update on dendritic cell-induced immunological and clinical tolerance. Front Immunol. (2017) 8:1514. doi: 10.3389/fimmu.2017.01514

123. Szondy Z, Sarang Z, Kiss B, Garabuczi É, Köröskényi K. Anti-inflammatory mechanisms triggered by apoptotic cells during their clearance. Front Immunol. (2017) 8:909. doi: 10.3389/fimmu.2017.00909

124. Wang Z, Larregina AT, Shufesky WJ, Perone MJ, Montecalvo A, Zahorchak AF, et al. Use of the inhibitory effect of apoptotic cells on dendritic cells for graft survival via T-cell deletion and regulatory T cells. Am J Transplant. (2006) 6:1297-311. doi: 10.1111/j.1600-6143.2006.01308.x

125. Kushwah R, Wu J, Oliver JR, Jiang G, Zhang J, Siminovitch KA, et al. Uptake of apoptotic DC converts immature DC into tolerogenic DC that induce differentiation of Foxp3 + Treg: Cellular immune response. Eur J Immunol. (2010) 40:1022-35. doi: 10.1002/eji.200939782

126. Niel G van, D'Angelo G, Raposo G. Shedding light on the cell biology of extracellular vesicles. Nat Rev Mol Cell Biol. (2018) 19:21328. doi: 10.1038/nrm.2017.125 
127. Théry C, Witwer KW, Aikawa E, Alcaraz MJ, Anderson JD, Andriantsitohaina R, et al. Minimal information for studies of extracellular vesicles 2018 (MISEV2018): a position statement of the International society for extracellular vesicles and update of the MISEV2014 guidelines. J Extracell Vesicles. (2018) 7:1535750. doi: 10.1080/20013078.2018.1535750

128. Théry C, Duban L, Segura E, Véron P, Lantz O, Amigorena S. Indirect activation of naïve CD4 $+\mathrm{T}$ cells by dendritic cell-derived exosomes. Nat Immunol. (2002) 3:1156-62. doi: 10.1038/ni854

129. André F, Chaput N, Schartz NEC, Flament C, Aubert N, Bernard J, et al. Exosomes as potent cell-free peptide-based vaccine. I. Dendritic cell-derived exosomes transfer functional MHC class I/peptide complexes to dendritic cells. J Immunol. (2004) 172:2126-36. doi: 10.4049/jimmunol.172.4.2126

130. Gonzalez-Nolasco B, Wang M, Prunevieille A, Benichou G. Emerging role of exosomes in allorecognition and allograft rejection. Curr Opin Organ Transplant. (2018) 23:22-7. doi: 10.1097/MOT.0000000000000489

131. Ma B, Yang J-Y, Song W, Ding R, Zhang Z, Ji H, et al. Combining exosomes derived from immature DCs with donor antigen-specific treg cells induces tolerance in a rat liver allograft model. Sci Rep. (2016) 6:32971. doi: 10.1038/srep32971

132. Pêche H, Renaudin K, Beriou G, Merieau E, Amigorena S, Cuturi MC. Induction of tolerance by exosomes and short-term immunosuppression in a fully MHC-mismatched rat cardiac allograft model. Am J Transplant. (2006) 6:1541-50. doi: 10.1111/j.1600-6143.2006.01344.x

133. Robbins PD, Morelli AE. Regulation of immune responses by extracellular vesicles. Nat Rev Immunol. (2014) 14:195-208. doi: 10.1038/nri3622

134. Ochando J, Braza MS. Nanoparticle-based modulation and monitoring of antigen-presenting cells in organ transplantation. Front Immunol. (2017) 8:1888. doi: 10.3389/fimmu.2017.01888

135. Etzerodt A, Maniecki MB, Graversen JH, Møller HJ, Torchilin VP, Moestrup SK. Efficient intracellular drug-targeting of macrophages using stealth liposomes directed to the hemoglobin scavenger receptor CD163. J Control Release. (2012) 160:72-80. doi: 10.1016/j.jconrel.2012.01.034

136. Bahmani B, Uehara M, Jiang L, Ordikhani F, Banouni N, Ichimura T, et al. Targeted delivery of immune therapeutics to lymph nodes prolongs cardiac allograft survival. J Clin Invest. (2018) 128:4770-86. doi: 10.1172/JCI120923

137. Shirali AC, Look M, Du W, Kassis E, Stout-Delgado HW, Fahmy TM, et al. Nanoparticle delivery of mycophenolic acid upregulates PD-L1 on dendritic cells to prolong murine allograft survival. Am J Transplant. (2011) 11:2582-92. doi: 10.1111/j.1600-6143.2011.03725.x

138. Maldonado RA, LaMothe RA, Ferrari JD, Zhang AH, Rossi RJ, Kolte $\mathrm{PN}$, et al. Polymeric synthetic nanoparticles for the induction of antigenspecific immunological tolerance. Proc Natl Acad Sci USA. (2015) 112:E15665. doi: 10.1073/pnas.1408686111

139. Zhang Y, Shen S, Zhao G, Xu CF, Zhang HB, Luo YL, et al. In situ repurposing of dendritic cells with CRISPR/Cas9-based nanomedicine to induce transplant tolerance. Biomaterials. (2019) 217:119302. doi: 10.1016/j.biomaterials.2019.119302

140. Zhang Q, Ichimaru N, Higuchi S, Cai S, Hou J, Fujino M, et al. Permanent acceptance of mouse cardiac allografts with CD40 siRNA to induce regulatory myeloid cells by use of a novel polysaccharide siRNA delivery system. Gene therapy. (2015) 22:217-26. doi: 10.1038/gt.2014.119

141. Iberg CA, Hawiger D. Advancing immunomodulation by in vivo antigen delivery to DEC-205 and other cell surface molecules using recombinant chimeric antibodies. Int Immunopharmacol. (2019) 73:57580. doi: 10.1016/j.intimp.2019.05.037

142. Iberg CA, Jones A, Hawiger D. Dendritic cells as inducers of peripheral tolerance. Trends Immunol. (2017) 38:793-804. doi: 10.1016/j.it.2017.07.007
143. Hawiger D, Inaba K, Dorsett Y, Guo M, Mahnke K, Rivera M, et al. Dendritic cells induce peripheral $\mathrm{T}$ cell unresponsiveness under steady state conditions in vivo. J Exp Med. (2001) 194:769-79. doi: 10.1084/jem.194.6.769

144. Bonifaz L, Bonnyay D, Mahnke K, Rivera M, Nussenzweig MC, Steinman RM. Efficient targeting of protein antigen to the dendritic cell receptor DEC-205 in the steady state leads to antigen presentation on major histocompatibility complex class I products and peripheral CD8 $+\mathrm{T}$ cell tolerance. J Exp Med. (2002) 196:1627-38. doi: 10.1084/jem.20021598

145. Reeves PLS, Rudraraju R, Wong FS, Hamilton-Williams EE, Steptoe RJ. Antigen presenting cell-targeted proinsulin expression converts insulinspecific CD8+ T-cell priming to tolerance in autoimmune-prone NOD mice. Eur J Immunol. (2017) 47:1550-61. doi: 10.1002/eji.201747089

146. Ettinger M, Gratz IK, Gruber C, Hauser-Kronberger C, Johnson TS, Mahnke $\mathrm{K}$, et al. Targeting of the hNC16A collagen domain to dendritic cells induces tolerance to human type XVII collagen. Exp Dermatol. (2012) 21:3958. doi: 10.1111/j.1600-0625.2012.01474.x

147. Ten Brinke A, Hilkens CMU, Cools N, Geissler EK, Hutchinson JA, Lombardi G, et al. Clinical use of tolerogenic dendritic cells-harmonization approach in european collaborative effort. Mediators Inflamm. (2015) 2015:471719. doi: 10.1155/2015/471719

148. Ochando J, Ordikhani F, Jordan S, Boros P, Thomson AW. Tolerogenic dendritic cells in organ transplantation. Transpl Int. (2020) 33:1137. doi: $10.1111 /$ tri. 13504

149. Bouchet-Delbos L, Even A, Varey E, Saïagh S, Bercegeay S, Braudeau C, et al. Preclinical assessment of autologous tolerogenic dendritic cells from end-stage renal disease patients. Transplantation. (2020). doi: 10.1097/TP.0000000000003315. [Epub ahead of print].

150. Sawitzki B, Harden PN, Reinke P, Moreau A, Hutchinson JA, Game DS, et al. Regulatory cell therapy in kidney transplantation (The ONE Study): a harmonised design and analysis of seven non-randomised, single-arm, phase $1 / 2 \mathrm{~A}$ trials. Lancet. (2020) 395:1627-39. doi: 10.1016/S0140-6736(20)30167-7

151. Feng S, Ekong UD, Lobritto SJ, Demetris AJ, Roberts JP, Rosenthal P, et al. Complete immunosuppression withdrawal and subsequent allograft function among pediatric recipients of parental living donor liver transplants. JAMA. (2012) 307:283-93. doi: 10.1001/jama.2011.2014

152. Benítez C, Londoño MC, Miquel R, Manzia TM, Abraldes JG, Lozano JJ, et al. Prospective multicenter clinical trial of immunosuppressive drug withdrawal in stable adult liver transplant recipients. Hepatology. (2013) 58:1824-35. doi: 10.1002/hep.2 6426

153. Zahorchak AF, Macedo C, Hamm DE, Butterfield LH, Metes DM, Thomson AW. High PD-L1/CD86 MFI ratio and IL-10 secretion characterize human regulatory dendritic cells generated for clinical testing in organ transplantation. Cell Immunol. (2018) 323:9-18. doi: 10.1016/j.cellimm.2017.08.008

Conflict of Interest: The authors declare that the research was conducted in the absence of any commercial or financial relationships that could be construed as a potential conflict of interest.

Copyright (c) 2020 Que, Guo and Li. This is an open-access article distributed under the terms of the Creative Commons Attribution License (CC BY). The use, distribution or reproduction in other forums is permitted, provided the original author(s) and the copyright owner(s) are credited and that the original publication in this journal is cited, in accordance with accepted academic practice. No use, distribution or reproduction is permitted which does not comply with these terms. 